\title{
Small bowel obstruction: a review of 264 cases and suggestions for management
}

\author{
Alexander A. Deutsch ${ }^{1}$, Ephraim Eviatar ${ }^{2}$, Haim Gutman ${ }^{1}$ and Raphael Reiss ${ }^{1}$ \\ ${ }^{1}$ Department of Surgery B, Beilinson Medical Center, Petah Tiqva, Sackler School of Medicine, Tel Aviv University \\ and ${ }^{2}$ Wolfson Hospital, Tel Aviv, Israel.
}

\begin{abstract}
Summary: Two hundred and sixty-four cases of acute small bowel obstruction were retrospectively reviewed for the purpose of defining factors which could point to the presence of strangulated bowel. History, physical signs and investigations, including body temperature, X-rays, white blood count, and serum amylase, were not significantly difierent in the simple and strangulated groups. Although an elevated urinary white blood count and a palpable mass were more common in the strangulated group, they were not sufficiently reliable for early diagnosis of strangulation.

In reviewing the literature, it is clear that all hernias with obstruction must undergo emergency surgery. Cases with intra-abdominal complete intestinal obstruction should also undergo emergency surgery. A more conservative attitude can only be taken when there is incomplete obstruction.
\end{abstract}

\section{Introduction}

Small bowel obstruction remains a common and serious clinical problem with a significant morbidity, and a mortality which may reach up to $30 \%$ in patients with strangulated bowel. ${ }^{1,2}$ Delay in surgical treatment may cause serious complications. ${ }^{3}$ In spite of a marked increase in diagnostic capabilities, it is still difficult to differentiate between simple obstruction, which may resolve with conservative measures, and bowel strangulation, where delay in surgery can lead to catastrophe.

We have reviewed all cases of small intestinal obstruction presenting to a general hospital over a 10-year period $(1971-1980)$ with a view to finding pointers which would indicate when strangulation is present. This information could facilitate the decision on surgery in any specific case or help develop a basic clinical policy in the management of these patients.

\section{Clinical material}

Over the 10-year period 1971-1980, 264 cases were admitted to a general hospital with a diagnosis of small intestine obstruction. The diagnosis was based on history, physical examination, abdominal radiology, operative findings and post-mortem examination. Cases of paralytic ileus, vascular occlusions and incarcerated hernias which reduced spontaneously on

Correspondence: H. Gutman, M.D., Dept of Surgery B, Beilinson Medical Center, Petah Tiqva 49100, Israel.

Accepted: 19 January 1989 admission were excluded. All cases in the series had definite $\mathrm{X}$-ray or surgical findings compatible with the diagnosis.

Case notes were carefully examined as to outcome, and all information relating to preadmission history, physical findings, $\mathrm{X}$-rays and laboratory tests was examined. Statistical analysis using Chi square was used calculating $P$ values for one degree of freedom.

\section{Results}

One hundred and ninety-four patients underwent surgery $(73.5 \%)$ of whom 145 had simple obstruction and 49 gangrenous obstruction which required resection of bowel. The remaining 70 patients resolved with conservative treatment $(26.5 \%)$.

There were 152 males and 112 females, a ratio of 1:1.36. Ages varied from birth to 92 years, with a mean of 54.34 years (Table I). One hundred and twentyseven cases had had a previous laparotomy $(48 \%)$. The causes of intestinal obstruction in the patients who came to surgery are shown in Table II.

Hernia (including incisional hernia), was the commonest cause in 85 cases $(43.8 \%$ ), of which 22 were strangulated. Seventy cases with adhesions fell into the non-strangulated subgroup, compared to 63 with hernia. History included abdominal pain in 259 patients $(98.1 \%)$, vomiting in 210 cases $(79.5 \%)$ (Table III). A palpable abdominal mass was found in a greater number of cases in the non-hernia strangulated subgroup than in those without strangulation $(P=0.014)$ (Table IV).

C The Fellowship of Postgraduate Medicine, 1989 
Table I Age distribution of 264 cases of intestinal obstruction

\begin{tabular}{lcccr}
\hline & $\begin{array}{c}\text { Non- } \\
\text { strangulated } \\
\text { Age }\end{array}$ & $\begin{array}{c}\text { Strangulated } \\
\text { (145 cases) }\end{array}$ & $\begin{array}{c}\text { Conservative } \\
\text { treatment } \\
(70 \text { cases })\end{array}$ & Total \\
\hline $0-10$ & 6 & 5 & 0 & 11 \\
$11-20$ & 8 & 1 & 0 & 9 \\
$21-30$ & 9 & 2 & 5 & 16 \\
$31-40$ & 15 & 5 & 4 & 24 \\
$41-50$ & 18 & 6 & 15 & 39 \\
$51-60$ & 26 & 8 & 10 & 44 \\
$61-70$ & 36 & 11 & 15 & 62 \\
$71-80$ & 21 & 9 & 14 & 44 \\
$81-90$ & 6 & 2 & 6 & 14 \\
$91-100$ & 0 & 0 & 1 & 1 \\
\hline
\end{tabular}

Table II Aetiology of obstruction in 194 surgical cases (Some cases had more than one aetiology)

\begin{tabular}{lccc}
\hline & $\begin{array}{c}\text { Non-strangulated } \\
(145 \text { patients })\end{array}$ & $\begin{array}{c}\text { Strangulated } \\
(49 \text { patients })\end{array}$ & $P$ \\
\hline Hernia & $63(43 \%)$ & $22(45 \%)$ & \\
Adhesions & $70(48 \%)$ & $13(27 \%)$ & 0.007 \\
Tumour & $9(6 \%)$ & $4(8 \%)$ & \\
Volvulus & 5 & 2 & \\
$\begin{array}{l}\text { Intussusception } \\
\text { Internal hernia }\end{array}$ & 0 & 7 & \\
$\begin{array}{l}\text { Phytobezoar } \\
\text { Intestinal } \\
\text { diverticulum }\end{array}$ & $2(1.4 \%)$ & $4(8.2 \%)$ & 0.017 \\
$\begin{array}{c}\text { Intraluminal } \\
\text { obstruction }\end{array}$ & $1(0.7 \%)$ & $3(6.1 \%)$ & 0.020 \\
$\begin{array}{c}\text { Gallstone } \\
\text { ileus }\end{array}$ & 3 & 0 & \\
$\begin{array}{l}\text { Omphalocoele } \\
\text { Omp }\end{array}$ & 0 & 0 & \\
\hline
\end{tabular}

Tachycardia above 100/minute and leucocytosis on over $10 \times 10^{9} / 1$ were little different in all groups. The urine amylase level was examined in all patients and $\mathrm{\varrho}$ was significantly raised in patients with obstruction due to adhesions $(P<0.018)$ compared to all other symptoms and signs in this subgroup. Temperature. above $38^{\circ} \mathrm{C}$ occurred in 11 cases, $4.2 \%$ of strangulated and $2.0 \%$ of the non-strangulated obstruction group:o

Urine sediment was examined in all patients. Theo presence of white blood corpuscles in the urine wase found in a total of 115 cases; 29 of these were in theo strangulated group $(59.2 \%)$, and 56 in the nonstrangulated cases $(38.6 \%),(P=0.01)$.

Abdominal X-rays were performed on 207 of the $\vec{\circ}$ 264 cases. They were unhelpful in differentiating between non-strangulated and strangulated cases.

Seventy of the cases treated by nasogastric tube, ando intravenous fluids resolved without surgery $(26.5 \%) .3$ A trial of conservative therapy was attempted in onlyos 203 cases, with success in $34.5 \%$.

The average time from first symptom to surgery was 3.5 days in the subgroup with non-strangulated ob- struction and 5.8 days in the strangulated group.

Postoperative complications occurred in $7.2 \%$ of allo patients, with some having several complications(Table V). Septic complications were significantlye higher in the strangulated cases. The mortality rate was $17 \%$ of operated cases ( 33 deaths), 19 occurred $i n_{\overrightarrow{0}}$ the non-strangulated group $(13.1 \%)$ and 14 in the strangulated group $(28.6 \%)(P=0.012)$. Advanced malignancy was causative in 13 cases, 9 nos strangulated and 4 strangulated. The average age of the patients who died was 65.2 years which waso significantly higher than the average age of the surviv- $\frac{}{\Phi}$ ing patients $(52.2$ years, $P=0.001)$.

Table III Symptoms of 264 patients with small bowel obstruction

\begin{tabular}{lccccr}
\hline Group & Abdominal pain & Vomiting & Constipation & Nausea & Total \\
\hline Non-strangulated & $141(97 \%)$ & $118(81 \%)$ & $78(54 \%)$ & $40(28 \%)$ & $145(100 \%)$ \\
Strangulated & $48(98 \%)$ & $38(78 \%)$ & $27(55 \%)$ & $14(29 \%)$ & $49(100 \%)$ \\
Conservative & $70(100 \%)$ & $54(77 \%)$ & $37(53 \%)$ & $17(24 \%)$ & $70(100 \%)$ \\
\hline
\end{tabular}

Table IV Physical signs of 264 patients with small bowel obstruction

\begin{tabular}{lcccccc}
\hline Group & Tenderness & $\begin{array}{c}\text { Rebound } \\
\text { tenderness }\end{array}$ & Guarding & $\begin{array}{c}\text { Abdominal } \\
\text { mass }\end{array}$ & $\begin{array}{c}\text { Abdominal } \\
\text { wall hernia }\end{array}$ & Total \\
\hline Non-strangulated & 129 & 39 & 29 & 6 & 63 & 145 \\
& $(89 \%)$ & $(27 \%)$ & $(19 \%)$ & $(4 \%)$ & $(43 \%)$ & $(100 \%)$ \\
Strangulated & 47 & 16 & 12 & 7 & 20 & 49 \\
Conservative & $(96 \%)$ & $(33 \%)$ & $(25 \%)$ & $(14 \%)$ & $(41 \%)$ & $(100 \%)$ \\
& 67 & 10 & 7 & 1 & 14 & 70 \\
& $(96 \%)$ & $(14 \%)$ & $(10 \%)$ & $(1.4 \%)$ & $(20 \%)$ & $(100 \%)$ \\
\hline
\end{tabular}


Table V Complications following surgery on 149 cases of intestinal obstruction

\begin{tabular}{lccc}
\hline Complication & $\begin{array}{c}\text { Non-strangulated } \\
\text { (145 cases) }\end{array}$ & $\begin{array}{c}\text { Strangulated } \\
\text { (49 cases) }\end{array}$ & Total \\
\hline Pneumonia & 23 & 7 & 30 \\
Wound dehiscence & 21 & 6 & 27 \\
Wound infection & 14 & 8 & 22 \\
Urinary tract & 12 & 4 & 16 \\
$\quad$ infection & 2 & 9 & 11 \\
Abdominal sepsis & 9 & 1 & 10 \\
Cardiac & 19 & 14 & 33 \\
Deaths & & & \\
\hline
\end{tabular}

\section{Discussion}

Wangensteen ${ }^{4}$ stressed the importance of early recognition of strangulated bowel, followed by immediate operation. Sarr et al. ${ }^{5}$ carried out a prospective study on 51 patients with obstructed small bowel. They found that no preoperative clinical parameters were sensitive, specific or predictive for strangulation. In addition, a senior surgeon predicted strangulation preoperatively in only 10 of 21 patients. In a series of 405 patients reported by Bizer et al. ${ }^{6}$ there was positive correlation for bowel strangulation in patients over 70 , in those with faeculent vomiting, in the absence of bowel sounds and in patients with a blood white count above $18 \times 10^{9} / 1$. There was no correlation with pain, duration of symptoms, temperature, tachycardia or X-ray findings. They conclude that despite the correlation, accurate criteria for small bowel strangulation have not been clearly defined.

Lefall and Syphax ${ }^{2}$ examined 74 patients with strangulated bowel and found that abdominal tenderness and raised temperature were present in over $50 \%$ of cases, and that tachycardia was a factor in $70 \%$ with a raised white blood count being present in $64 \%$ of the series.

However, in the series of 50 patients with strangulated obstruction compared with 53 nonstrangulated patients reported by Shatatila et al., ${ }^{7}$ the classic picture with fever, tachycardia and leucocytosis was absent in $70 \%, 42 \%$ and $42 \%$, respectively.

Stewardson et al. ${ }^{8}$ found that nearly $90 \%$ of patients had at least two of the classical signs of strangulation. Silen et al. ${ }^{9}$ reviewed 480 patients with small bowel obstruction, and found the classical signs absent in strangulated cases, which was similar to the review of 349 cases of Zollinger and Kinsey. ${ }^{10}$ Some authors have found that over $80 \%$ of cases of strangulation were not suspected preoperatively. ${ }^{11}$

The overall conclusion must be that initial signs of strangulation are minimal and, when present, they reflect advanced changes associated with infection and sepsis.

Our own series has similarly been unsuccessful in diagnosing strangulated bowel, but a palpable abdominal mass was found in $14.3 \%$ of strangulated cases as against $4.1 \%$ in simple obstruction $(P=0.014)$. This was more pronounced in malignant cases $(21.4 \%)$. Shatilla et al..$^{7}$ found the presence of a mass more common in strangulation, but Davis and Sperling ${ }^{11}$ did not find this to be the case.

A raised urinary white cell count in $59.2 \%$ of cases with strangulation as against $38.6 \%$ in the simple cases $(P=0.010)$ has not been recorded elsewhere. The significance of this is not clear though it may also be associated with systemic septic changes.

$A$ raised amylase level in the urine was found in significantly raised frequency in cases of obstruction due to adhesions, compared to cases in which another aetiology was responsible for the obstruction. This was not found in other series reviewed. ${ }^{7,8,12}$ Temperature changes above $38^{\circ} \mathrm{C}$ were not found to any significant extent, and was an unhelpful sign. The failure of X-rays of the abdomen to assist in differentiating between non-strangulated and strangulated bowel confirms the findings in other series. ${ }^{16.7}$

Conservative therapy was successful in 70 cases in our series, $39 \%$ of the non-hernia cases. Both Bizer et $a l .{ }^{6}$ and Broline ${ }^{13}$ found no difference in the outcome whether a nasogastric or nasointestinal tube was used. We used the shorter nasogastric for decompression. Laws et al.,$^{14}$ however, did find some indications for the use of the longer Miller-Abbot tube for decompression.

Broline $^{13}$ reviewed 91 cases of partial intestinal obstruction out of a total of 175 obstruction cases. Eighty-eight percent of the partial obstruction group were managed successfully by decompression alone. In the series of Bizer et al., ${ }^{6}$ only $28.3 \%$ of non hernia cases settled without surgery although, in this series, they did not differentiate between partial and complete obstruction.

Hernia was the commonest cause of obstruction in our series $(43.8 \%$ of operated cases) with adhesions second $(42.8 \%$ of operated cases) and malignancy third. These results would be more in keeping with findings in the third world. ${ }^{15,16}$ Series reported from western countries have adhesions as the main cause with hernia often reduced to third place after malignancy. ${ }^{6,11,14}$ The explanation is probably our inclusion of all hernias which were incarcerated with small bowel. There is considerable flexibility in inclusion criteria in different series, which leads to confusion when comparing one series to another. It would probably be better to review series of adhesive obstruction from other causes of intestinal obstruction.

Morbidity was higher in the strangulated group and the period of hospitalization was longer, both of which 
concur with other reports. ${ }^{7,8}$ Sepsis was much higher in the strangulated group ( $18.4 \%$ as against $1.4 \%)$ and wound infection was more common, although not significantly so. Other series have conflicting results. ${ }^{6,17}$

Mortality in our series is high at $12.9 \%$ of all the 264 cases, and $28.6 \%$ in cases of strangulation. Most recent series report levels of $4 \%,{ }^{7} 5.5 \%{ }^{8}$ and $8 \% .^{14}$ However, Lo et al..$^{12}$ report a mortality of $24 \%$. The mortality in cases with strangulation varies from $14.6 \%{ }^{6}$ to $4.5 \%,{ }^{8}$ but levels of $30 \%,{ }^{2} 32 \%{ }^{17,18}$ and $38 \%{ }^{12}$ have also been reported. Reasons for this high mortality include a long delay in reaching hospital, and the older age of the patients with fatal complications. Our series has a high proportion of patients with strangulation, up to $18.6 \%$ of series compared to $10 \%$ in the series of Bizer et al. ${ }^{6}$ There was a particularly high mortality among the patients with malignant disease and several of the neonatal cases had other severe abnormalities. If the 13 malignant cases were excluded, the mortality results would read $10.9 \%$ overall, $9.6 \%$ simple obstruction and $24 \%$ with strangulation.

More recently, Otomiri et al ${ }^{19}$ reviewed 128 cases operated for adhesive obstruction. They concluded that early surgery was indicated in most of these patients. Pain et al.$^{20}$ however, used a multivariate computer analysis retrospectively on 197 patients with

\section{References}

1. Barnett, W.O., Petro, A.B. \& Willimason, J.W. A current appraisal of problems with gangrenous bowel. Ann Surg 1976, 183: 653-659.

2. Lefall, L.D. \& Syphax, B. Clinical aids in strangulation intestinal obstruction. Am J Surg 1970, 120: 756-759.

3. Playforth, R.H., Holloway, J.B. \& Groffen, W.O. JR. Mechanical small bowel obstruction: A plea for earlier surgical intervention. Ann Surg 1970, 171: 783-788.

4. Wangensteen, O.H. Understanding the bowel obstruction problem. Am J Surg 1978, 135: 131-149.

5. Sarr, M.G., Bulkley, G.B. \& Zuidava, G.D. Preoperative recognition of intestinal strangulation obstruction. Am J Surg 1982, 145: 176-182.

6. Bizer, L.S., Leibling, R.W., Delaney, H.M. \& Gliedman, M.L. Small bowel obstruction. Surgery 1981, 89: 407-413.

7. Shatatila, A.H., Chamberlain, B.E. \& Webb, W.R. Current status of diagnosis and management of strangulation obstruction of the small bowel. Am J Surg 1976, 132: $299-303$.

8. Stewardson, R.H., Bombeck, C.T. \& Nyhus, C.M. Cortical operative management of small bowel obstruction. Ann Surg 1978, 187: 189-193.

9. Silen, W., Hein, M.F. \& Goldman, L. Strangulation obstruction of the small intestine. Arch Surg 1962, 85: $121-129$.

10. Zollinger, R.M. \& Kinsey, D.L. Diagnosis and management of intestinal obstruction. Am Surgeon 1964, 30: $1-5$. small bowel obstruction. They felt that the computê? could contribute to the management of these patientso

\section{Conclusions}

Differentiation between simple obstructed small bowe and gangrenous bowel either by clinical or laborator methods seems impossible at an early stage. Even during surgery the decision can be very difficult. This is why tests such as Doppler or fluorescein tests havê been suggested to help preoperative decisions..$^{21,22} \mathrm{~W}$ would suggest the following policy guidelines: (1) Alt hernias which are obstructing must underge् immediate surgery; (2) Other cases with complete obstruction should undergo surgery if they do not resolve within the few hours used for preoperative preparation; (3) Cases with partial obstruction can ber followed for 24 hours, with immediate surgery fo 5 cases which show progressive or complete obstruction

Although we have been unable to show anything new in the management of this extremely commop condition, it is still important not to be complacent and to treat small bowel obstruction very seriously This alone may reduce the relatively high complicatio迹 rate.

11. Davis, S.E. \& Sperling, L. Obstruction of the smalf intestine. Arch Surg 1969, 99: 424-426.

12. Lo, A.M., Evans, W.E. \& Carcy, L.C. Review of smaî bowel obstruction of Milwaukee General Hospital. Am $\mathcal{L}_{2}$ Surg 1966, 111: 884-887.

13. Brolon, R.E. Partial small bowel obstruction. Surger 1984, 95: 145-149.

14. Laws, H.L. \& Aldrete, J.S. Small bowel obstruction: review of 465 cases. South Med J 1976, 69: 733-734. $\bar{\partial}$

15. Chakrabarty, P.B., Tripathy, B.C. \& Parda, K. Acute intestinal obstruction (a review of 1020 operated cases). $\not$ Indian Med Assoc 1976, 67: 64-69.

16. Chidozi, L.C., Aboh, I.O. \& Peserchia, N.E. Mechanica\$ bowel obstruction. Review of 316 cases in Benin City Am J Surg 1980, 139: 389-393.

17. Ghanem, M., Goodaly, R.L., Spanos, P., Tsung, M.S. \& Wangensteen, O.H. Value of leukocyte count in the recognition of mesenteric infarction and strangulation os. short intestinal lengths. An experimental study. Surger w 1970, 68: 635-645.

18. Snyder, E.N. \& McCranie, D. Closed loop obstruction of the small bowel. Am J Surg 1966, 111: 398-402.

19. Otomiri, T., Sjodahl, R. \& Inse, I. Intestinal obstruction with strangulation of the small bowel. Acta Chir Scand 1987, 153: $307-310$.

20. Pain, J.A., Collier, D. St. J. \& Hanka, R. Small bowe obstruction: computer-assisted prediction of strangulation at presentation. Br J Surg 1987, 74: 1-981-983. T 
21. Bulkley, G.B., Zuidema, G.D., Hamilton, S.R., O'Mara, C.S., Klacsman, P.G. \& Horn, S.D. Intraoperative determination of small intestinal viability following ischemic injury. Ann Surg 1981, 193: 628-637.
22. Hobson, I.I. R.W., Wright, C.B., O'Donnell, J.A., Jamil, Z., Lambeth, W.C. \& Nohem, Z. Determination of intestinal viability by Doppler ultrasound. Arch Surg 1979, 114: 165-168. 